\title{
Assessment of Preformed 3D-Thermoplastic Road Markings for Long - term Durability, Skid Resistance and Texture Functionality
}

\author{
${ }^{1}$ Kalpesh Purohit, ${ }^{2}$ Mujib Rahman, ${ }^{3}$ Andrew Price, ${ }^{4}$ Alan Woodside \\ 1,2,4 Department of Civil and Environmental Engineering \\ Brunel University London \\ ${ }^{3}$ Preformed Markings Ltd \\ 6, Oyster Park, 109 Chertsey Rd, Byfleet, West Byfleet KT14 7AX
}

\begin{abstract}
Road Markings are an important safety feature for directing and guiding traffic without distracting its drivers. The erosion of the marking material as a result of prolonged exposure to rain and traffic actions, greatly reduce their performance. In this paper, results from field and laboratory investigations on innovative preformed thermoplastic road markings sheet with 3D impressions are presented. An immersion wheel tracking test was conducted in the laboratory for evaluating material effectiveness against stripping in long-term exposure to water and traffic loading. The results showed that preformed sheet installed on preheated and non-heated asphalt surfaces are capable of withstanding long (20,000 cycles) exposure of continuous traffic while submerged in water. Overall, the thermoplastic sheet installed in both conditions, demonstrated excellent performance against stripping, although the performance was relatively better when installed on the pre-heated surface. Furthermore, one-year field observations showed that preformed marking installed on asphalt and concrete surface retains their macrotexture, maintains excellent dry and wet frictions. The 3D impression was also found beneficial on drivers' behavior for speed reduction. Depending on the vehicle type, the reduction was $20-31 \%$ immediately after installation and $9-17 \%$ after one year. Overall, this study suggests that preformed thermoplastic road marking is not only a durable product but also 3D illusion provides some traffic calming benefits.
\end{abstract}

Keywords: 3D Road Marking, Preformed Thermoplastic Road Marking, Sand Patch, Skid Resistance, Long Term Performance, stripping resistance. 


\section{Introduction}

The underlying motivation behind road markings is to direct and manage the traffic on a highway (Highways Act 1980). They increase the function of traffic signs, fill in as a mental hindrance and guide traffic to maintain lateral clearance from traffic hazards for the safe and smooth movement of vehicles. Pavement markings area unit is classified into two broad classes by service functions, particularly by removable and non-removable. The former type encompasses a comparatively short service life (less than a year) and is employed with temporary traffic patterns; whereas the later one encompasses a longer service life (more than one year) and is employed with permanent traffic patterns.

There are three key types of permanent road markings. Marking to show longitudinal lane or edge lines, stop lines or crossover markings, and other unique markings such as arrows, words, image markings, cross-hatching, speed hump markings, and automobile parking space markings. They are available in various configurations and styles, creating it visible for drivers and pedestrians to instantly acknowledge and quickly react for safe and efficient use of the road. Presently, there are a variety of road marking materials are widely used. These are solvent and water-based paints, polyester, thermoplastic, epoxy, alkyl radical methacrylate, preformed thermoplastic, and preformed tape (Traffic sign manual, 2018, IS EN 1436, 2004). The performance of road marking depends on the surface porosity, surface type and material used in the marking (Scottish Road Research Board, 2015, Sheik et al 2015, Naidoo S and Steyn M, 2018).

The price of road marking materials varies depending on their formulation and availability but they all must ensure two fundamental characteristics. The color of the marking must be distinguishable from the underlying surface and must be detectable even in harsh weather. Furthermore, they should apply to a range of different pavement surfaces and must be strong enough to undergo harsh traffic and climatic conditions.

The focus of this study is on permanently installed preformed 3D pavement markings. In recent years preformed thermoplastic marking is gaining popularity in an urban environment due to their flexibility in installation. The preformed marking combined with 3D that generates the illusions which appear to be more effective in controlling driving behaviors. Presently, there are some good industrial practices where 3D marking demonstrated good performances over traffic reduction and safety and better durability than conventional paintbased road marking (Sheikh et al. 2015). The future of this type of marking is also promising as road marking will be vital for the implementation of autonomous vehicles and ensuring road safety when both driver-assisted and selfdriving vehicles will be sharing the same road space (Stefan et al, 2007). Moreover, if 3D marking proved effective for long-term traffic calming, this could 
either be used to replace and/or supplement traffic cameras as a traffic control measure.

The objective of this paper is to investigate the functional, and long-term laboratory and field performance of preformed thermoplastic material. A comprehensive laboratory and field investigation was conducted to measure dry and wet friction, macrotexture and immersion wheel tracking tests to measure stripping resistance and degradation properties over time. Furthermore, two 3D thermoplastic 15Mph signs were installed at the campus to evaluate their on-site functional properties and effectiveness as a traffic calming measure.

\section{3D Preformed Thermoplastic Road Marking}

3D-Preformed thermoplastic markings consist of pigments, reflective glass beads, fillers, binders and additives (PREMARK, 2012). Pigments are fundamentally acquainted with imparting color to supply characteristics, like ultraviolet stability. The filler material is a combination of carbonate, sand, and different inert materials. The binder component used in the marking sheet is resin-based and does not change with chemicals on heating and application. Finally, the plasticizer is used as an additive to ensure the durability and flow of the material during the manufacturing process.

The preformed sheet is manufactured adding $30 \%$ reflective glass beads by weight mixed along with the melted thermoplastic material. Further beads are added from the top once the marking is installed. The typical thickness of the 3D preformed marking is between $2.29 \mathrm{~mm}$ or $5.50 \mathrm{~mm}$ (DMRB, 2008). An image of typical 3D marking is given in Figures $1 \mathrm{a}$ and $1 \mathrm{~b}$.

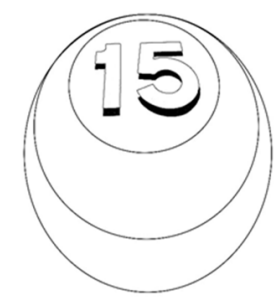

Fig 1a: Schematic diagram of 3D marking

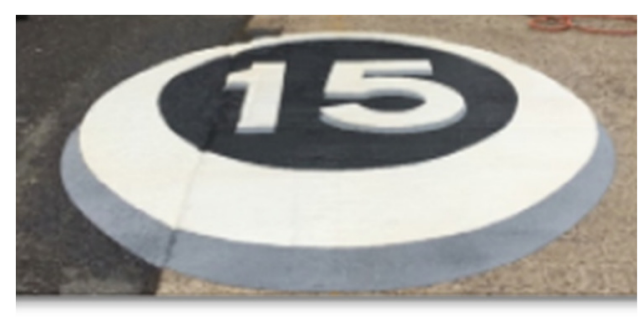

Fig 1b: 3D thermoplastic marking

\section{Experimental Program}

\subsection{Functional properties}

The testing program consisted of evaluating functional properties such as Sand patch test according to ASTM E965 for macro texture measurement, Pendulum test according to ASTM E303-93 to measure frictional properties in dry and in wet conditions (Traffic Sign Manual, 2012, ASTM, 2018, AASHTO, 2004, Elisabete et al., 2018, Anon, 2012). Furthermore, the marking was cut into $750 \mathrm{~mm}$ by $450 \mathrm{~mm}$ size and was 
installed on $750 \mathrm{mmX} 450 \mathrm{mmX} 100 \mathrm{~mm} 20 \mathrm{~mm}$ Asphalt concrete slab. Two types of installation processes were followed. The first one was installed on the unheated surface and in the second one, a preheating for approximately 5minutes was applied on the asphalt surface prior to placing the mat. Both methods then followed similar heating approximately $193^{\circ} \mathrm{C}$ according to manufacturer procedure for site installation.

\subsection{Stripping resistance}

Two slabs from each case were then tested in dry and in the submerged condition in the Hamburg wheel tracking machine according to AASHTO T324-04 for 20,000 passes at room temperature $18^{0} \mathrm{C}+/-2^{0} \mathrm{C}$. This test allowed evaluating the stripping resistance, material degradation, and deformation due to wheel tracking (AASHTO, 2004). It is important to note that, the specifications in AASHTO T324 were modified to allow large specimen $(750 \mathrm{~mm} \times 300 \mathrm{~mm} \times 100 \mathrm{~mm})$ testing instead of $150 \mathrm{~mm}$ diameter circular specimens. This was necessary to test the large size of the thermoplastic installation simulative to field conditions.

\subsection{On-site testing}

In parallel, two $1.5 \mathrm{~m}$ size $3 \mathrm{D}$ markings were installed on campus road to study the functional properties and long-term performance in the outside environment as well as their effectiveness in traffic calming. The installation sequence is given in Figure 2. The first marking was installed on the concrete-asphalt surface with joints in the middle and the second was on the concrete pavement. The site was chosen to evaluate the performance of the 3D marking on different surfaces including the influence of joint on long-term performance. As shown in Figure 2, the installation procedure consisted of thoroughly cleaning the road surface and then apply preheating to dry out surface moisture (Figure a-b). The discussion with the manufacturer pointed out that in a typical installation, the preheating stage is left to weather conditions and budget of the project. Following preheating, a primer was applied (Figure 2c) prior to placing the marking segments on the road surface (Figure 2d). It was ensured that all parts of the preformed markings are in contact with each other. The final stage involved applying heating up to 190-2000C to fuse the mat into the pavement surface (Figure 2e). Careful attention was given in the joints between the segments and in the joints between asphalt and concrete pavement. The finished installation (Figure 2f) was left for further 15 minutes to cool down to the surrounding temperature. The whole operation of installation for one marking took approximately 30 minutes.

\section{Results and Analysis}

\subsection{Visual observation of installed 3D marking}

The visual survey was conducted at 3 and 12 months and results are presented in Table 1. The road marking observed for 365 days showed no visible sign of disintegration, cracking or loss of visibility. A picture of the marking after 12 months is given in Figure 3. The tire stain marks spotted @ 3 months was found superficial and washed away with rain. Overall, the visual appearance did not change after 12 months. The 
excellent day and night visibility after 12 months indicate good retro-reflectivity of the material. Furthermore, material near the joints, as shown in Figure 3, showed no sign of failure, indicating a good bond even at the edges.

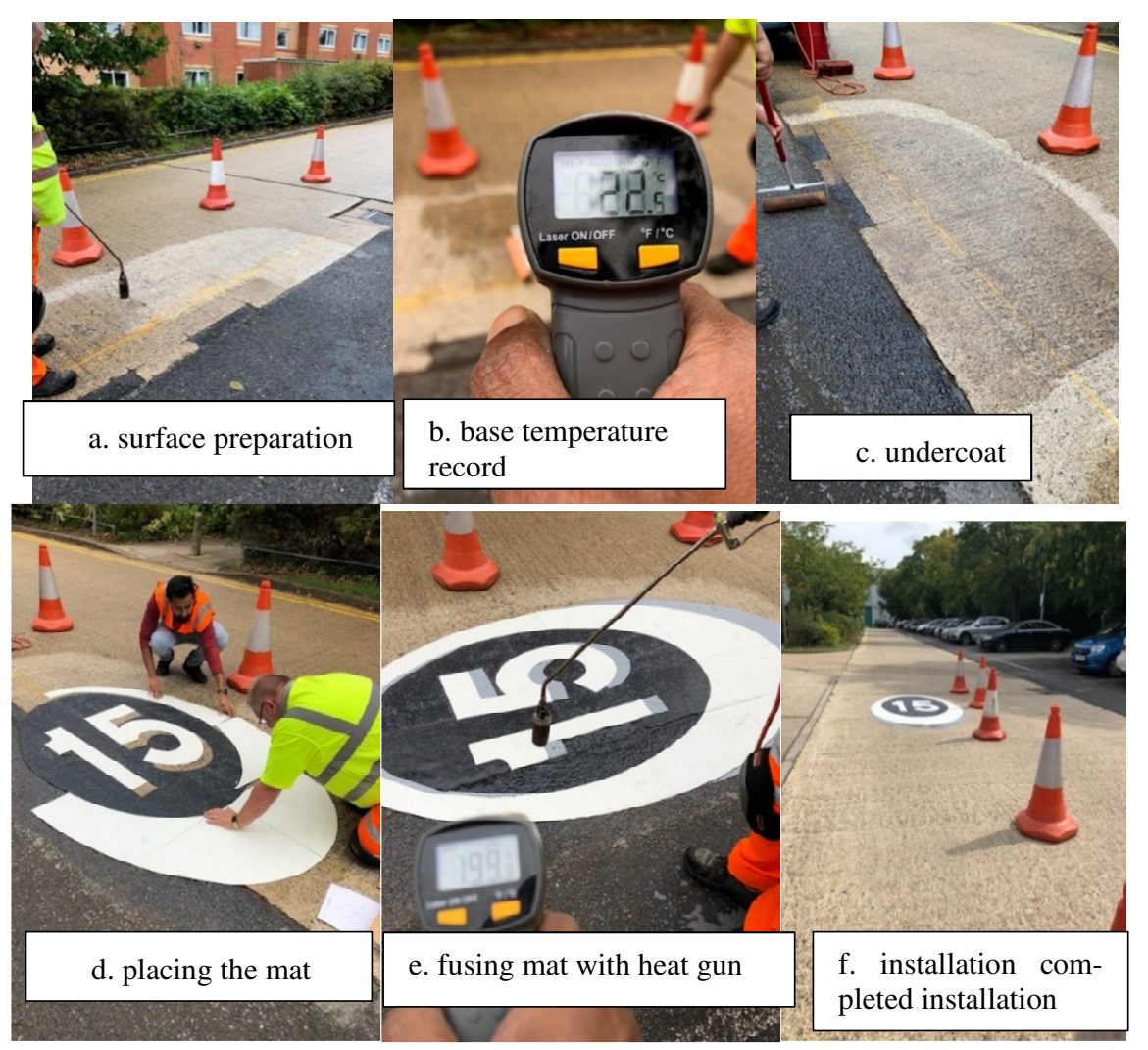

Fig 2: 3D preformed marking installation procedure

Table 1: Visual condition data

\begin{tabular}{lccc} 
Observation & \multicolumn{4}{c}{$\begin{array}{c}\text { Condition } \\
\text { (X= none, Y=few, Z= significant, E=excellent) }\end{array}$} \\
\cline { 2 - 4 } & $\begin{array}{c}\text { day 1 } \\
\text { (Aug 18) }\end{array}$ & $\begin{array}{c}\text { 3 months } \\
\text { (Jan 19) }\end{array}$ & $\begin{array}{c}\text { 12 months } \\
\text { (Sep 19) }\end{array}$ \\
\hline Surfacing cracking & $\mathrm{X}$ & $\mathrm{X}$ & $\mathrm{X}$ \\
\hline Material disintegration & $\mathrm{X}$ & $\mathrm{X}$ & $\mathrm{X}$ \\
\hline Stain on the surface & $\mathrm{X}$ & $\mathrm{Y}$ & $\mathrm{X}$ \\
\hline Tire mark & $\mathrm{X}$ & $\mathrm{Y}$ & $\mathrm{X}$ \\
\hline 3D impression & $\mathrm{Z}$ & $\mathrm{Z}$ & $\mathrm{Z}$ \\
\hline Visibility at daytime & $\mathrm{E}$ & $\mathrm{E}$ & $\mathrm{E}$ \\
\hline Visibility at night-time & $\mathrm{E}$ & $\mathrm{E}$ & $\mathrm{E}$
\end{tabular}




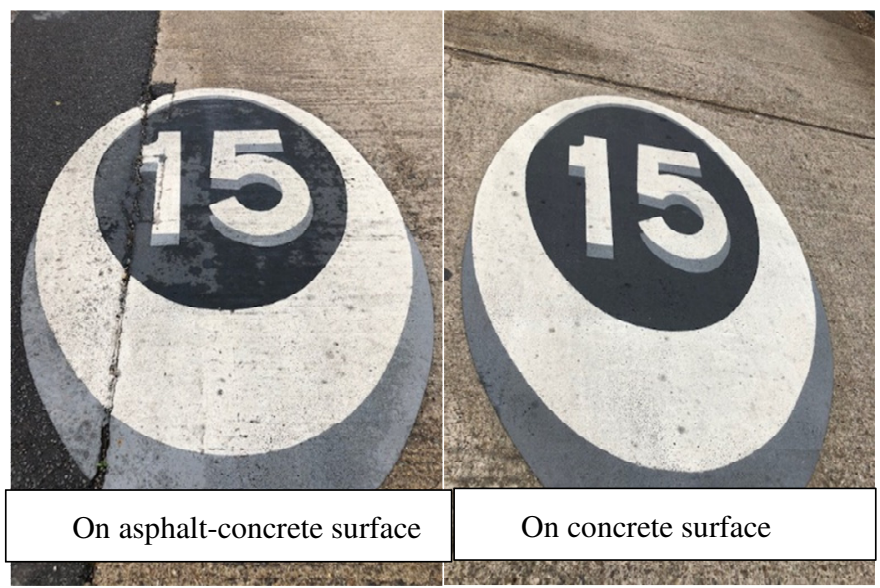

Fig 3: Installed 3D marking after 12 months

\subsection{Macro texture}

The macrotexture of the 3D marking before installation and periodically measured nine months after installation is given in Table 2. As expected, the texture depth in the asphalt surface was found higher than the concrete surface. On average, the texture value reduced approximately $1-1.15 \mathrm{~mm}(10-22 \%)$ from preinstalled to @ day 1 installed value. This was due to heat applied during installation, which reduces the overall thickness of the mat. The changes from day one to after 12 months is relatively constant, the reduction is less than $5 \%$, indicating stable performance under traffic loading and environmental cycles.

Table 2: Macro texture properties

\begin{tabular}{|c|c|c|c|c|c|}
\hline \multirow{3}{*}{$\begin{array}{l}\text { Base } \\
\text { surface }\end{array}$} & \multicolumn{5}{|c|}{ Macro texture depth (mm) } \\
\hline & \multirow[t]{2}{*}{ Statistics } & \multirow{2}{*}{$\begin{array}{l}\text { Surrounding } \\
\text { pavement }\end{array}$} & \multicolumn{3}{|c|}{ On the marking } \\
\hline & & & day 1 & 3 months & 12 months \\
\hline \multirow[t]{3}{*}{ Asphalt } & Ave & 4.13 & 4.0 & 3.9 & 3.8 \\
\hline & $\operatorname{Max}$ & 4.26 & 4.1 & 4.2 & 4.1 \\
\hline & Min & 4.03 & 3.8 & 3.7 & 3.6 \\
\hline \multirow[t]{3}{*}{ Concrete } & Ave & 3.13 & 2.8 & 2.8 & 2.7 \\
\hline & $\operatorname{Max}$ & 3.26 & 3.0 & 3.1 & 3.0 \\
\hline & Min & 3.03 & 2.4 & 2.6 & 2.4 \\
\hline
\end{tabular}




\subsection{Frictional properties}

The dry and wet pendulum test results from day one to after twelve months are given in Table 3. The installation on both asphalt-concrete and concrete surface gives average slip resistance value (SRV) as 80-90 for preformed thermoplastic marking in dry condition and 66-73 in wet condition. Which still is considerably higher than generally recommended 55 in the design standards in the UK (DMRB, 2008). Looking at the empirical values the skid resistance value for the Concrete pavement is marginally higher than that of asphalt pavement. The presence of glass bits in the thermoplastic sheet gives high frictional resistance. It is interesting to note that the frictional values change less than $10 \%$ in all surface installation even after 365 days of trafficking.

Table 3: Dry and Wet friction

\begin{tabular}{|c|c|c|c|c|c|c|c|}
\hline \multirow{4}{*}{$\begin{array}{l}\text { Base } \\
\text { surface }\end{array}$} & \multirow{4}{*}{$\begin{array}{l}\text { Statistical } \\
\text { value }\end{array}$} & \multicolumn{6}{|c|}{ Friction } \\
\hline & & \multicolumn{6}{|c|}{ After installation } \\
\hline & & \multicolumn{2}{|c|}{ day 1} & \multicolumn{2}{|c|}{3 months } & \multicolumn{2}{|c|}{12 months } \\
\hline & & dry & wet & dry & wet & dry & wet \\
\hline \multirow[t]{3}{*}{ Asphalt } & Ave & 84.2 & 69 & 85 & 70 & 81.3 & 68 \\
\hline & $\operatorname{Max}$ & 85.2 & 70 & 90 & 72 & 84.3 & 72 \\
\hline & Min & 82.3 & 68 & 80 & 68 & 78.5 & 66 \\
\hline \multirow[t]{3}{*}{ Concrete } & Ave & 90.4 & 73 & 90 & 71 & 82.5 & 69 \\
\hline & Max & 95.1 & 75 & 95 & 73 & 84.1 & 72 \\
\hline & Min & 89.0 & 70 & 85 & 69 & 79.3 & 64 \\
\hline
\end{tabular}

\subsection{Long-term performance in accelerated laboratory test}

The test set-up for wheel tracking and tested samples after 20,000 cycles are given in Figure 4, and in Table 4, the visual conditions of the tested samples are explained. The rutting overserved in the testing (Figure 4) is related to asphalt material, therefore, it was not included to assess the performance of thermoplastic. The result showed that in both non-preheated and pre-heated cases (Table 4), there was no evidence of stripping or material disintegration in the dry test. However, there was some evidence of stripping on the non-heated case when tested submerged condition. On the other hand, no stripping or deterioration was noted in the preheated installation. This indicates that marginally better adhesion due to preheating.

The stripping inflexion point was calculated by subtracting the intercept of the first portion of the deformation vs load cycles plot from the 2 nd portion of the same graph and then divided by the slope of the first portion minus the slope of the second portion. As reported in Table 4, no striping was evident in the dry test. However, in the submerged test, as discussed earlier, minor evidence of stripping was noted towards the end of the test in the non-heated case. 

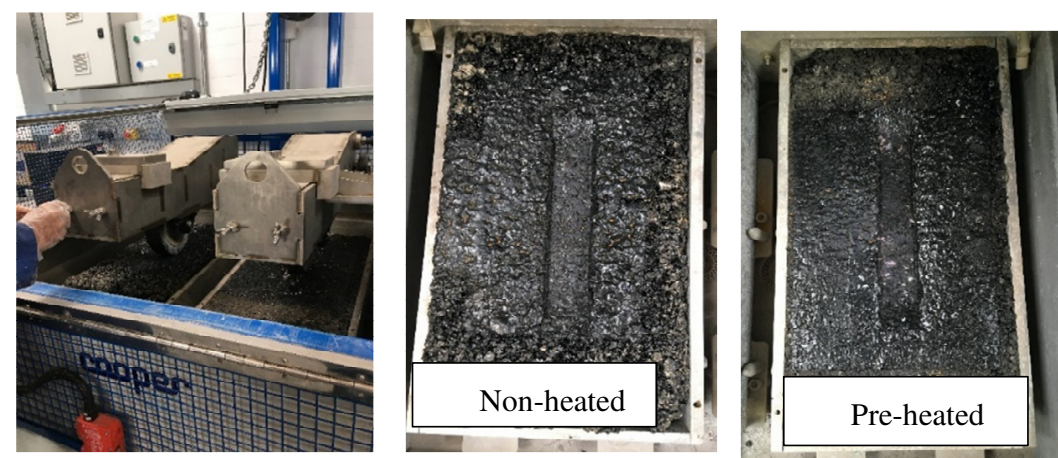

Fig 4: Modified Hamburg wheel tracking test

Table 4: Visual observation of tested slabs after 20,000 cycles

\begin{tabular}{|c|c|c|c|c|}
\hline \multirow[t]{2}{*}{ Case } & \multicolumn{2}{|c|}{ Visual condition after 20,000 cycles } & \multicolumn{2}{|c|}{$\begin{array}{l}\text { Stripping inflexion } \\
\text { point @ number of } \\
\text { passes }\end{array}$} \\
\hline & Dry test & Submerged & Dry & Submerged \\
\hline $\begin{array}{l}\text { Installed on } \\
\text { non-heated } \\
\text { surface }\end{array}$ & $\begin{array}{l}\text { No evidence of mate- } \\
\text { rial stripping, surface } \\
\text { crack etc. }\end{array}$ & $\begin{array}{l}\text { Evidence of } \\
\text { some stripping }\end{array}$ & none & $\sim 18,000$ \\
\hline $\begin{array}{l}\text { Installed on } \\
\text { pre-heated } \\
\text { surface }\end{array}$ & $\begin{array}{l}\text { No evidence of mate- } \\
\text { rial stripping, surface } \\
\text { crack etc. }\end{array}$ & $\begin{array}{l}\text { No evidence of } \\
\text { stripping }\end{array}$ & none & none \\
\hline
\end{tabular}

\subsection{Traffic calming evaluation}

The main aim of this survey was to identify the response of the driver towards the road marking installed on the university campus. A similar survey was conducted on the same location before the installation of the marking to test the average speed of the vehicles. The results showed that, despite road signs displayed at the side of the road, the vehicles run at an average speed varying from $17 \mathrm{mph}$ to $22 \mathrm{mph}$ exceeding the University premises speed limit of $15 \mathrm{mph}$.

The procedure for the survey included calculation of the speed of the vehicles going past the installed road marking. Since the average speed was in the range of $17 \mathrm{mph}$, it was assumed that the initial velocity of the vehicle is $17 \mathrm{mph}$ and the final velocity value determined the response. To calculate the final velocity, a constant distance, i.e. $40 \mathrm{~m}$ from start to end (standard amidst which lies the marking was taken). After this, the time taken by the vehicle to cross that distance was observed for different types of vehicles. The measurements were done during the morning (8.30-10 am) and afternoon rush hour (between $4.30 \mathrm{pm}$ to $5.30 \mathrm{pm}$ ). The average speed for cars and transit vans, the most frequent types of vehicles on the campus, are presented in Table 5. 
Table 5: Average speed of vehicle

\begin{tabular}{|c|c|c|c|c|c|}
\hline \multirow[t]{2}{*}{ Vehicle } & \multirow{2}{*}{$\begin{array}{l}\text { Average } \\
\text { speed at 40m } \\
\text { to 3D mark- } \\
\text { ing (mph) }\end{array}$} & \multicolumn{4}{|c|}{$\begin{array}{l}\text { Average speed near the marking } \\
(\mathrm{Mph})\end{array}$} \\
\hline & & $\begin{array}{l}\text { day } \\
1 \\
\end{array}$ & $\begin{array}{l}1 \\
\text { month }\end{array}$ & $\begin{array}{l}3 \\
\text { months }\end{array}$ & $\begin{array}{l}12 \\
\text { months }\end{array}$ \\
\hline Cars (110 no) & 18.6 & 12.90 & 14.3 & 14.2 & 15.3 \\
\hline Transit Vans (25 no) & 17.5 & 14.07 & 15.3 & 16.7 & 15.8 \\
\hline
\end{tabular}

The results showed that, depending on the vehicle type, speed reduction was $20-31 \%$ reduction after 1 day of installation and that reduced to $9-17 \%$ after 12 months. As the campus road is predominantly used by students, staffs, and visitors, regular over speeding used to take place before installation of 3D marking. The 3D impression likely gives a road humps illusion, and driver reacts even the marking location is known to them. This could be an effective and low-cost alternative to speed camera or road humps. Further large-scale trials on different roads and traffic conditions are required to verify this.

\section{Conclusions}

Key conclusions from this investigation are;

- 3D thermoplastic road marking does not reduce texture in asphalt and concrete surfaces. The texture depth remains relatively constant and likes the surrounding pavement even after 12 months of trafficking.

- The average wet and dry slip resistance value (SRV) of 3D marking were found between 65-90 at the start and remain relatively constant after 12 months. These values are significantly higher than conventional asphalt and concrete surfaces and indicate very good frictional properties in the installed area.

- The consistent day and night-time visibility of the marking ensure good retro-reflectivity. The vehicle speed measurement also showed speed reduction even after 12 months in service, indicating the long-term effectiveness of the marking in traffic calming operation.

- The thermoplastic material installed on non-heated and pre-heated asphalt surfaces showed good performance against accelerated wheel tracking tests. The dry and submerged condition testing showed that the mat installed in the pre-heated surface has marginally better performance than non-heated surfaces. The preheating was also applied during the field installation.

- The overall conclusion from this investigation is that 3D preformed thermoplastic markings is a durable product and have demonstrated some benefits in traffic calming operation in a small-scale trial and can supplement traffic camera as a means for traffic control measure. Furthermore, the long-term durability of 3D marking ensures less intervention and, therefore less disruption to the traffic. 
Acknowledgements The authors would like to express their appreciation to the Preformed Markings Ltd UK for providing supports during this project.

\section{References}

1. Highways Act 1980, Legislation.gov.uk, 1980

2. Traffic Sign Manual, Road Marking, Department of Transport, United Kingdom, 2018

3. Lekshmi Sasidharan, Vishesh Karwa, Eric T. Donnell, Use of Pavement Marking Degradation Models to Develop a Pavement Marking Management System Public Works Management \& Policy 14(2):148-173, 2009

4. American Society for Testing and Materials. Standards Designations E-274, E-501, E965, E-1845, E-1960 and E-2157. In Annual Book of ASTM Standards (CD-ROM) Volume 04.03, 2001.

5. American Society for Testing and Materials. Standard Designations E-303 - 93, Standard Test Method for Measuring Surface Frictional Properties Using the British Pendulum Tester, 2018

6. AASHTO T 324, Hamburg Wheel-Track Testing of Compacted Hot Mix Asphalt (HMA), 2004

7. F.G.Praticò and R.Vaianab, A study on the relationship between mean texture depth and mean profile depth of asphalt pavements, Construction and Building Materials, Volume 101, Part 1, P72-79, 2015.

8. PREMARK, Specifications and MSDS Sheet, Preformed Thermoplastic - Melt Down Road \& Pavement Striping. [online] Available at: http://preformedthermoplastic.com/premark-specifications-and-msds-sheet/ [Accessed 5 Oct. 2018], 2012

9. DMRB, Volume 7, Section 3, Standards for Highways, 2008

10. Songquan Wang, Comparative analysis of NTPEP pavement marking performance evaluation results, MSc dissertation, https://etd.ohiolink.edu/rws_etd/document/get/akron1271369205/inline, 2010

11. IS EN 1436 European Standard for Road Marking, 2004

12. Anon (2012). PREMARK®. [online] Available at: https://www.preformedmarkings.co.uk/traffic-applications/premarkr/ [Accessed 5 Oct. 2018].

13. Scottish Road Research Board, Durability of White Thermoplastic Road Markings, 2015

14. Sheikh Azhar U Rehman and A.K Duggal, Comparative Analysis of Pavement Marking Material based on Retro-Reflectivity International Research Journal of Engineering and Technology (IRJET) Volume: 02 Issue:05, 2015.

15. Stefan Vacek, Constantin Schimmel and R"udiger Dillmann, Road-marking analysis for autonomous vehicle guidance, European Conference on Mobile Robots, September 1921, Freiburg, Germany, 2007

16. Tatyana Brusentseva*, Vladislav Shikalov and Vasiliy Fomin, Cold spray deposition of thermoplastic powder for road marking, EPJ Web of Conferences, 2019.

17. Naidoo S an Steyn M, Performance of thermoplastic road-marking material, Journal of South African Institution of Civil Engineering, ISSAN 1021-2019,Col: 60, No 2, Paper 1584, P9-22, 2018 